\title{
COLABORAÇÃO: PERSPECTIVAS dA FAMÍLIA E dO TERAPEUTA QUANTO A UMA TERAPIA ÚTIL*
}

\author{
COLLABORATION: FAMILY AND THERAPISTS' PERSPECTIVES OF HELPFUL \\ THERAPY
}

ROLF SUNDET

Departamento de Saúde, Universidade de Buskerud,

Noruega

CARLOS HENRIQUE B. DE LUCE Tradutor

* Original em Sundet, $\mathrm{R}$. (2011). Collaboration: Family and therapists' perspectives of helpful therapy. Journal of Marital and Family Therapy, 37(2), 236-249.
RESUMO: Este estudo qualitativo examinou como um grupo de famílias e seus terapeutas descreveram uma terapia útil. A análise qualitativa apresentou perspectivas da família e do terapeuta. Como uma dupla descrição, as perspectivas do terapeuta e da família valorizaram a conversação, participação e o relacionamento como as três áreas centrais de uma terapia útil. Estas estão especificadas por categorias e subcategorias que focam as atividades de compartilhamento de experiências, contribuição do próprio conhecimento e envolvimento pessoal, a formulação e reformulação de perguntas e o feedback correspondente. A discussão de similaridades e diferenças entre as perspectivas provê uma descrição do que constitui uma boa terapia para as famílias e terapeutas, apontando para a expansão de modelos que têm norteado os terapeutas.

PALAVRAS-CHAVE: Gregory Bateson; epistemologia cibernética; estética; terapia sistêmica; intuição; identidade do terapeuta.
ABSTRACT: This qualitative study examined how a group of families and their therapists described helpful therapy. The qualitative analysis generated family and therapist perspectives. As a double description, the therapist- and family perspectives highlighted conversation, participation and relationship as three core areas of helpful therapy. These are specified by categories and subcategories that center upon activities of sharing experiences, contributing own knowledge and personal involvement, posing questions, reformulating and giving feedback, and specifying the therapeutic relationship as a relationship of collaboration. Discussion of similarities and differences between the perspectives provides a description of what constitutes good therapy for the families and therapists and points to expansion of the models that have guided the therapists.

KEYWORDS: Gregory Bateson; cybernetic epistemology; aesthetics; systemic therapy; intuition; self of the therapist.

As pesquisas já confirmaram a eficácia da psicoterapia (Lambert \& Ogles, 2004). Rennie (1992) salienta a importância de tornar a experiência do cliente na prática terapêutica acessível, e The American Psychological Association (APA, 2006) defende uma perspectiva múltipla dos métodos de pesquisa. Estas perspectivas sugerem uma importante pergunta para investigação: o que os pacientes consideram ser uma terapia útil. Isso é particularmente importante nas práticas que, tradicionalmente, não são avaliadas por pesquisas clínicas. Relatórios quanto ao que é útil são um passo a um conhecimento dessas práticas, embora não respondam às questões quanto à eficácia.

Três abordagens de terapia familiar são importantes no trabalho aqui apresentado. São elas: a abordagem colaborativa de sistemas linguísticos, de Anderson e Goolishian (1988); o trabalho de equipe e processos reflexivos, de Andersen (1991), e a prática narrativa, de White (2007). O foco na colaboração e na linguagem (Andersen, 1991; Anderson \& Gehart, 2007; White, 2007), bem como uma ênfase na valoração das perspectivas dos pacientes (Andersen, 1991; Anderson, 
1996, White, 2007), constituem os denominadores comuns entre as três abordagens. Todas elas fazem parte da mudança para as ideias pós-modernas e pós-estruturalistas conectadas com o giro linguístico na filosofia (Flaskas, 2002).

Bennet (2008) e Gehart-Brooks, Ratliff e Lyle (2001) documentaram o fato de que praticamente apenas pesquisa qualitativa tem sido feita sobre esses métodos - o que foi exemplificado pelos seguintes estudos: Smith, Yoshioka e Winton (1993) e Smith, Winton e Yoshioka (1992), os quais examinaram as opiniões dos clientes e terapeutas de equipes reflexivas para um melhor entendimento dos benefícios desse tipo de trabalho. Sells, Smith, Coe, Yoshioka e Robbins (1994) e Smith, Sells e Clevenger (1994) prosseguiram nesse enfoque com o objetivo de produzir categorias descritivas detalhando os significados latentes, crenças e compreensão de como os participantes entendiam o trabalho das equipes reflexivas. London, Ruiz e Gargollo (1998) apresentaram três relatos de clientes sobre as experiências dos mesmos em relação à abordagem colaborativa de Goolishian. Anderson, Gehart-Brooks e Lyle (1999) investigaram o processo de mudança nesse tipo de trabalho através das experiências dos clientes e terapeutas. O'Connor, Meakes, Pickering e Schumman (1997) relataram os aspectos úteis, os significados e as percepções das famílias participantes da prática narrativa. O'Connor, Davis, Meakes, Pickering e Schumman (2004) exploraram as experiências dos terapeutas que utilizavam a prática narrativa. Comum a todos esses estudos qualitativos é o foco deles em um método específico, seja o de equipe reflexiva, método colaborativo ou narrativo, com exceção de O'Connor et al. (2004), que estudou o uso de equipes reflexivas dentro de uma prática narrativa. Lambert, Bergin e Garfield (2004) apontaram para uma "... tendência crescente entre terapeutas a não se limitarem a um único sistema de tratamento baseado em uma abordagem puramente teórica" (p. 6). Em uma posição eclética, ideias e procedimentos de diferentes campos são usados, o que está afinado com as ideias do campo de terapia familiar pós-moderno (Mcnamee, 2004). Tendo por base esse campo, o terapeuta deve estar pronto a ir além de um único método. $\mathrm{O}$ foco principal deste estudo é explorar essa questão através da investigação de como uma prática guiada por três métodos orientados pela pós-modernidade foi experimentada e descrita como útil pelos participantes. Ademais, as seguintes questões foram levantadas: O que acontece com os tipos de práticas baseadas nesses métodos quando usadas por famílias e terapeutas? Quais as diferenças e similaridades entres as perspectivas das famílias e dos terapeutas? Como elas se complementam?

\section{ESTUDO}

\section{Contexto}

O contexto deste estudo é $A$ Unidade da Família, uma combinação de tratamento diurno com a unidade ambulatorial familiar do Departamento de Psiquiatria da criança e do adolescente em um hospital norueguês. A unidade recebe encaminhamentos de médicos, serviços pedagógicos, saúde escolar e agências de proteção à criança. É um serviço público de saúde mental composto por 5 terapeutas e com um apartamento residencial à disposição da instituição. Com um tratamento diurno associado ao ambulatório, a Unida- 
de pode oferecer um tratamento ambulatorial tradicional e suplementá-lo com uma estadia no apartamento por um período máximo de três semanas. O tratamento pode ser divido em três períodos: um período preparatório com trabalho ambulatorial, que consiste na discussão das necessidades, preferências e metas específicas dos pacientes e culmina com a decisão sobre como continuar o tratamento juntos. Caso uma estadia no apartamento for julgada apropriada na conclusão do período preparatório, o mesmo será disponibilizado por um período máximo de três semanas, durante as quais a família trabalha junto com dois terapeutas das 9:00 às 15:00, de terça a sexta-feira. Após essa fase, a unidade oferece serviço ambulatorial padrão de acordo com as necessidades e preferências da família. Nessas condições, uma variedade de meios de interação entre os terapeutas e a família pode ser implementada.

As razões que levam ao encaminhamento de uma família para a Unidade da Família são duas: a família manifesta o desejo de trabalhar como uma família ou uma agência de encaminhamento faz a recomendação. Para a admissão de crianças e adolescentes, um diagnóstico é obrigatório. Os diagnósticos mais comuns são Desvio ou Transtorno de Conduta, Transtorno do Déficit de Atenção com Hiperatividade (TDAH), Transtorno Obsessivo-Compulsivo (TOC) e outros problemas emocionais ou comportamentais. A maioria das famílias já tentou outros tipos de tratamento anteriormente, porém sem sucesso. Geralmente, há inúmeras questões contextuais relacionadas com o problema, tais como as derivadas da interação da criança ou adolescente com sua escola ou seu grupo etário. Os conceitos de situação de múltiplas escolhas e complexidade (Seikkula \& Arnkil, 2006) descrevem essa situação. O grupo de terapeutas é composto por profissionais altamente experientes com histórico em diversas áreas de prática e métodos terapêuticos.

\section{Participantes}

Foram entrevistadas trinta pessoas no total: quatro terapeutas (Tabela 1) e dez famílias: dez mães, cinco pais e onze crianças (Tabela 2). Gênero, idade, anos de experiência e profissão dos terapeutas são mostrados na Tabela 1 , enquanto que na Tabela 2 é retratado o tamanho das famílias entrevistadas, o estado ou situação das mesmas e quem foram os terapeutas. Todas as famílias e terapeutas são de etnia norueguesa.

Tabela 1

\begin{tabular}{|c|c|c|c|c|}
\hline Terapeuta & Gênero & Idade & Experiência & Profissão \\
\hline A & Masculino & 49 & 20 anos & $\begin{array}{c}\text { Psicólogo } \\
\text { Clínico }\end{array}$ \\
\hline B & Feminino & 63 & 27 anos & $\begin{array}{c}\text { Pedagogo } \\
\text { Clínico }\end{array}$ \\
\hline C & Masculino & 56 & 29 anos & $\begin{array}{c}\text { Assistente } \\
\text { Social }\end{array}$ \\
\hline D & Feminino & 47 & Estudante do $2^{\circ}$ ano & Estudante \\
\hline Pesquisador/autor & Masculino & 54 & 25 anos & $\begin{array}{c}\text { Psicólogo } \\
\text { Clínico }\end{array}$ \\
\hline
\end{tabular}


Tabela 2

\begin{tabular}{|c|c|c|c|c|c|c|c|}
\hline Famílias & Tamanho & Mãe & Pai & Filhos & Entrevistados & $\begin{array}{c}\text { Status do } \\
\text { tratamento }\end{array}$ & Terapeuta \\
\hline 1 & 3 & 1 & 1 & 1 & todos & Ativo & A e B \\
\hline 2 & 3 & 1 & & 2 & mãe, 1 filho & Ativo & C e D \\
\hline 3 & 5 & 1 & 1 & 3 & todos & Finalizado & B e D \\
\hline 4 & 3 & 1 & & 2 & todos & Ativo & A e B \\
\hline 5 & 2 & 1 & & 1 & mãe & Ativo & A e B \\
\hline 6 & 2 & 1 & & 1 & todos & Finalizado & A e X3 \\
\hline 7 & 4 & 1 & 1 & 2 & mãe e pai & Finalizado & A e B \\
\hline 8 & 3 & 1 & 1 & 1 & mãe & Finalizado & A e B \\
\hline 10 & 4 & 1 & 1 & 2 & todos & Ativo & A e B \\
\hline Total & 33 & 10 & 6 & 17 & $\begin{array}{c}10 \text { mães, } 5 \text { pais } \\
\text { e } 11 \text { filhos }\end{array}$ & $\begin{array}{c}5 \text { Ativos e } 5 \\
\text { finalizados }\end{array}$ \\
\hline
\end{tabular}

0 terapeuta X3 deixou de trabalhar na Unidade da Família antes do início do projeto.

As famílias foram recrutadas pelos terapeutas. Os critérios para a inclusão nas pesquisas foram: famílias com os dois pais ou apenas um, com tratamentos em andamento ou já finalizados. Todas as famílias concordaram em participar, sendo as mesmas informadas verbalmente e por escrito sobre o estudo; o pesquisador entrou em contato com as famílias somente após o consentimento delas.

$\mathrm{O}$ autor/pesquisador contatou as famílias por telefone e os pais escolheram uma entrevista individual ou como família. Também foram consultados se queriam a presença dos filhos nas entrevistas. Em caso afirmativo, os pais pediam aos filhos que participassem. Todas escolheram a entrevista familiar, exceto uma, cuja mãe quis participar, mas não o pai e o filho. Em uma família, as circunstâncias não permitiram a participação dos filhos; em outra, a mãe não quis que sua filha participasse. Em sete famílias os filhos estavam presentes. A participação dos filhos variou de uma integração ativa na entrevista até deixar os pontos principais a cargo de seus pais.

$\mathrm{O}$ autor era o quinto membro da Unidade da Família e integrou a práxis na qual os entrevistados faziam seus comentários. Isso significou que sua posição como participante do processo exigia uma maior conscientização de seus pressupostos subjetivos como pesquisador. As pesquisas tradicionais têm marginalizado a posição de quem está dentro de uma situação em favor de um argumento de quem está fora da mesma, que observa mais e melhor o que está ocorrendo. Schultz (1967, citado por Rennie, 2000, p. 484) sugere que "... quando comparado com o Outro, a pessoa que tem a experiência está em uma posição melhor para co- 
nhecer seu significado". Mal-entendidos podem ocorrer tão facilmente da perspectiva de um participante externo como interno; nas duas posições, os pesquisadores têm que explicitar sua subjetividade.

\section{Coleta de Dados}

Uma bem fundamentada análise teórica foi realizada. Os dados foram coletados através de uma entrevista com cada terapeuta e com cada família, as quais duravam de uma a quase duas horas, dependendo do tempo para se obter as informações necessárias. Guias de entrevista foram preparados e adaptados para os terapeutas, pais e crianças/adolescentes. Essas guias funcionaram como um fio condutor temático para as entrevistas (Kvale, 1996). Cinco áreas temáticas foram abordadas em todas as entrevistas: pensamentos/perspectivas sobre a terapia, ingredientes da terapia que foram importantes e úteis ou não, efeitos e resultados da terapia, recomendações sugeridas pela terapia e outras ideias ou associações não perguntadas anteriormente. Exemplos de perguntas às famílias incluíam: Como foi sua experiência com o trabalho da Unidade da Família? Que ideias você tinha sobre o tratamento? Houve algo que foi útil ou não a você? Você tem alguma recomendação a nos fazer? Para os terapeutas, as seguintes perguntas foram formuladas: Quais são seus meios preferidos de trabalho? Que ideias balizam seu trabalho? Foi perguntado a ambos os grupos: Existem áreas que não foram abordadas nesta entrevista e que gostariam de comentar? As entrevistas foram gravadas em áudio e posteriormente transcritas por um profissional e analisadas pelo autor.

\section{Análise}

Este estudo empregou modificações em teorias consagradas (Glaser \& Strauss, 1968) por Rennie, Phillips e Quartara (1988) e por Hill, Thompson e Williams (1997). As entrevistas foram organizadas em textos compostos de afirmações que constituíam blocos de dados (Hill et al., 1997) ou unidades de significado (Rennie et el., 1988). As unidades de significados foram organizadas em uma estrutura preliminar de acordo com os temas em comum, diferenciando áreas que formavam domínios específicos. O domínio que se segue foi elaborado a partir de uma organização inicial do material: forma do trabalho terapêutico, efeito da terapia, entendimento do trabalho terapêutico e um outro domínio para temas não relacionados à questão pesquisada. O próximo passo foi extrair a ideia principal (ex. a "essência" da afirmação) dentro de cada domínio (Hill et al., 1997). 110 ideias principais foram formuladas das entrevistas com os terapeutas e 577 das entrevistas com as famílias. Estas ideias foram comparadas com outros casos para a criação de categorias. Dois níveis de categorias foram escolhidos: categoria e subcategoria (Nerdrum \& Ronnestad, 2002).

Eis um exemplo:

E: Enfrentar algo no exato momento que ocorra. Parece que você já passou por isso. Você poderia me falar mais como você experimentou essa situação?

F: Isso deu a você a oportunidade de ter uma situação real na qual pode ter supervisão ou pode receber a confirmação de que o que você estava fazendo era o correto em uma a situação difícil, e ao mesmo tempo os terapeutas experimentavam quão difícil nosso dia a dia podia ser. 
Três temas do processo terapêutico foram identificados nessa sequência: oportunidades de supervisão pelo terapeuta, reafirmação à família por um profissional e a chance de o terapeuta experimentar as dificuldades familiares. Esses temas foram todos classificados como pertencentes ao domínio chamado "forma do trabalho terapêutico" e especificados como três ideias centrais distintas: oportunidade de supervisão, de reafirmação e de compartilhar experiências. Através de comparação constante de todas as ideias principais do estudo (Glaser \& Strauss, 1968), a primeira e a terceira no exemplo acima foram vistas como integrantes da "participação útil" pelas famílias. A primeira foi incluída em "usando o conhecimento profissional". Ainda dentro da perspectiva familiar, a segunda principal ideia fez parte do "relacionamento útil", sendo incluída em "criando colaboração".

O presente estudo teve um grupo-alvo definido: quatro terapeutas e famílias que preenchiam os critérios de seleção descritos acima. Os processos seguidos para identificação das experiências de tal grupo pré-definido foram os postulados por Hill et al. (1997). Hill et al. (1997) não utilizam amostragem teóricas (Glaster \& Strauss, 1968). Eles definem a amostragem e “... coletam todos os dados usando o mesmo protocolo para assegurar a constância da resposta dentro de uma amostra homogênea de participantes, ao invés de alternarem a coleta e análise dos dados..." (p. 521).

Saturação (Glaser \& Strauss, 1968) ou estabilidade de resultados (Hill et al., 1997) é alcançada se “... novos casos não alterem os resultados (Hill et al., 1997, p. 552). Em um processo no qual de 12 a 15 casos são coletados, uma análise preliminar de 8 a 12 é completada, e... se os casos restantes não mu- darem substancialmente o resultado, as conclusões podem ser consideradas seguras" (p. 553). As entrevistas com os terapeutas eram fixas (não havia outros a serem entrevistados), então a questão de saturação não se aplica. Uma análise preliminar foi finalizada com 8 famílias. As duas entrevistas seguintes não adicionaram nenhuma nova categoria. Assumimos, portanto, que o ponto de saturação foi atingido.

Hill et al. (1997) advogam o uso de grupos para estabelecer um consenso de análise, enquanto que Rennie (1992) defende o uso de um pesquisador como uma posição viável e mantém que consenso não é garantia de objetividade. Nesse estudo, o autor considerou legítimas as premissas de Rennie e as aplicou. Ao mesmo tempo, o uso de juízes externos foi considerado um meio importante para garantir vozes diferentes e a variedade de perspectivas no material. Dessa forma foi realizada a checagem com os participantes (Elliot, Fisher, \& Rennie, 1999). $\mathrm{O}$ autor apresentou o resultado a terapeutas e duas famílias acostumadas com suas práticas. Ambos os grupos aceitaram o resultado como descritivos de suas experiências.

\section{OS RESULTADOS}

\section{A perspectiva dos terapeutas}

A análise produziu duas descrições, uma baseada na perspectiva dos terapeutas e outra na das famílias. Em ambas os principais temas conectaram terapia útil com conversação, participação mútua e relacionamento terapêutico, embora esses temas tenham sido expressos por diferentes metáforas e conceitos. As seguintes metáforas - "sentir na pele", "conversa sem pressa e uma caixa grande de ferramentas" e 
"estar onde as pessoas estão" (Tabela 3) - explicam como os terapeutas descreveram a prática terapêutica que buscavam realizar na Unidade.

"Sentir na pele" destaca o uso das oportunidades de ter uma experiência similar às dos pacientes pelos terapeutas. Ela foi especificada nas seguintes subcategorias: compartilhar experiências, participar, atingir definições mútuas e diminuir as diferenças. As experiências de compartilhamento se relacionam ao terapeuta "estar na pele deles" e "sentir na própria pele" (Terapeuta A, daqui em diante T.A., T.B., etc). Ao trabalhar de perto com as famílias, os terapeutas descreveram como frequentemente eles experimentaram estar na mesma situação em que estavam as famílias que se sentiam impotentes ao lidarem com seus filhos. Os terapeutas também perceberam que era útil às famílias "verem outras pessoas lutarem com esses problemas...” (T.A.). Havia “...uma empatia mútua, você se sentia tocado e eles eram afetados pelo modo como eram compreendidos por nós" (T.A.).

Participação expressa uma ideia de mutualidade. "Se você não tem (uma participação mútua), é fácil para o terapeuta se ver como um especialista, o que pode fazer com que o envolvimento da família seja mais difícil"
(T.C). "Ao contrário... eu realmente tento tratá-los como especialistas e promover sua expertise". Por exemplo, em uma dramatização "troquei de papel, uma hora era o pai, o filho e eu mesmo. Tive que ter a ajuda da família sobre como as coisas haviam acontecido, o que eles haviam tentado e então obter as respostas deles sobre minhas ideias, que então tentamos" (T.A). Fazer coisas juntos leva a "outros modos de lidar com o problema... e determinar conjuntamente como trabalhar" (T.C.).

Atingir definições comuns é exemplificado pela seguinte afirmação: "Eles respondem e eu escolho levar isso a sério; isto, por sua vez, os afeta. Acho que existiu um processo de definição que continuou entre nós e eles" (T.A.). O objetivo neste processo de definição era descobrir o problema: "Com o que estamos lidando aqui?" (T.A.). Por meio de atividades verbais e não verbais os membros da família experimentaram "como se tivessem sido despertados gradualmente para o fato de serem pessoas que têm algo a dizer e (o problema) foi definido em palavras e tornado mais claro e explícito ..." (T.A.). Isto foi "uma troca de ideias" (T.A.) que gradualmente deu significado, definição e contextualização ao problema.

Tabela 3

\begin{tabular}{|c|c|c|}
\hline "Sentir na Pele" & $\begin{array}{c}\text { "Conversar sem pressa e } \\
\text { ter uma caixa grande de } \\
\text { ferramentas" }\end{array}$ & $\begin{array}{c}\text { "Estar onde as pessoas } \\
\text { estão" }\end{array}$ \\
\hline $\begin{array}{c}\text { Compartilhar } \\
\text { experiências }\end{array}$ & Questionar & $\begin{array}{c}\text { Ouvir. Falar seriamente } \\
\text { e acreditar }\end{array}$ \\
\hline Participar & Persistir & Ser flexível \\
\hline $\begin{array}{c}\text { Atingir definições } \\
\text { mútuas }\end{array}$ & Conteúdo & Generosidade \\
\hline $\begin{array}{c}\text { diminuir as } \\
\text { diferenças }\end{array}$ & Detalhar as nuances & \\
\hline
\end{tabular}


O foco na reciprocidade de experiências, participação e definição de significado expressou as similaridades das posições dos familiares e dos terapeutas. Nas palavras do T.A.: "Quando você troca ideias desta maneira, a importância de quem é ou não o especialista diminui. Gosto de apagar essas diferenças e (os membros das famílias) dizem que isso é encorajador." A característica principal do "sentir na pele" foi essa diminuição da diferença entre os familiares e seus terapeutas. Um efeito importante dessa similaridade de posições foi que isto implicou o compromisso por parte da família, uma vez que "você fez parte da tomada de decisão, tem que cumpri-la" (T.C.). $\mathrm{O}$ resultado dessa diminuição de diferenças foi um aumento do envolvimento familiar.

"Conversar sem pressa e ter uma caixa grande de ferramentas" aponta para dois processos interligados. Um relacionado com o uso da linguagem na formulação das questões, sem pressa; o outro na utilização de ferramentas terapêuticas e ter acesso a muitas destas. O ponto de partida para trabalhar na Unidade era "fazer boas perguntas que fizessem (a família) perceber outros modos de pensar" (T.B). Perguntas iniciam um caminho ao interior do mundo de eventos e significados da família. Geralmente isso envolve aspectos de suas vidas "que foram difíceis de serem postos em palavras. Era difícil para eles se entenderem entre eles mesmos e fazerem outros entenderem com o que estavam lutando" (T.A.). Nesta situação, "fazer perguntas cria uma certa distância e nos permite focar na situação, criando possibilidades de sintetizar e clarificar a mesma" (T.A.). Conversar sem pressa se relacionava com a forma com que as perguntas eram feitas. $\mathrm{O}$ aspecto decisivo era "ser capaz de demorar-se o suficiente, sem pressa. Criar longas conversas, ater-se apropriadamente por meio de uma escuta mais longa, um pouco mais longa... (então) em que eles precisavam se focar vinha à tona lentamente" (T.A.).

Ao mesmo tempo, o terapeuta queria ter acesso a uma variedade de técnicas. O T.B. introduziu a metáfora da "grande caixa de ferramentas" da seguinte forma:

"A questão de método, ou seja, como trabalhamos; não estávamos tão preocupados sobre as distinções entre terapia tradicional, de meio ambiente, ludoterapia, terapia de casal, familiar, individual... Utilizávamos tudo isto. Estávamos preocupados em ter uma caixa grande de ferramentas, com acesso a muitas coisas, muitas possibilidades, algo bem eclético. Escolhíamos o que melhor se adaptasse à família."

Essa prática nos levou a juntar vários métodos de acordo com as necessidades das famílias. Quando "aprendíamos algo novo ou buscávamos conselhos, estes vinham das famílias que nos informavam o que eles precisavam" (T.B.). O processo que levava à escolha de um método específico estava intimamente ligado às conversas longas que revelavam "o ponto de vista da família" (T.B.). Esta conexão ressalta a importância de se intercalar métodos e técnicas terapêuticos e conversação, alternando, continuamente, conversação, diálogo, ação, interação e a feitura de algo prático.

Após vários anos, os terapeutas desenvolveram uma variedade de técnicas que podiam utilizar. As mais mencionadas nesse estudo foram: o uso do flip chart e canetas como ferramentas para visualização e memorização, o uso de terapias específicas como o Programa de Treinamento de Pais - de Barkley (1997), prática narrativa (White, 2007), ferramentas usadas entre métodos específicos como o 
Genograma (McGoldrick, Gerson, \& Shellemberger, 1999) e o kit de Diálogo da Família (Balmbra, 2006). Dramatização, teatro de marionetes, jogos, fazer vídeos, uso de álbum de fotos e brincadeiras também fizeram parte da caixa de ferramentas. Por último, a Escala de Classificação da Sessão e a Escala de Classificação de Resultados (Miller \& Duncan, 2004) foram utilizadas para monitorar o processo e os resultados.

Tradicionalmente, a patologia tem sido o foco da saúde mental. Isto sugere ao terapeuta uma visão do paciente como sendo "sem particularidades" ou "falta de nuances". A declaração que se segue expressa uma posição diferente: "Eu nunca digo que vou mostrar o que você deveria fazer. Tento tratá-los como especialistas em tudo o que já tentaram e perceber as nuances ao redor de suas próprias nuances" (T.A.). Uma visão centralizada na patologia torna $o$ usuário do serviço da Unidade como sendo "sem particularidades", cabendo ao terapeuta especialista avaliar o que está errado. A terapia proporciona uma oportunidade de correção. Uma posição diferente estava implícita quando membros de uma família eram vistos "com particularidades". O problema não era que os clientes não tinham nuances, mas, sim, que não havia sido dada a eles a oportunidade de estimulá-las em suas vidas, por sinal, já cheias de singularidades. Embora essa interpretação seja baseada em uma única descrição, a centralidade de um ponto de vista não patológico na prática da Unidade garante essa posição como uma característica central da caixa de ferramentas do terapeuta.

"Estar onde as pessoas estão" era a ideia central dessa unidade e foi definida da seguinte forma: "trabalhar com aquilo que as pessoas querem trabalhar" (T.C.) e “...usar o ponto de partida da família” (T.D.). Tal postura foi especificada através dos termos: ouvir, levar a sério, acreditar, ser flexível e generoso. A experiência principal para esses terapeutas foi que "... as pessoas realmente experimentavam isso como algo positivo. Era... ser cuidado" (T.C.) e "sentir que eles haviam sido compreendidos naquilo que era mais importante para eles" (T.B.). Os terapeutas conectaram o ser ouvido de um modo satisfatório com as seguintes ações: levar em conta e acreditar no que as pessoas apresentavam. "Era fundamental observar seriamente os pequenos sinais de que algo estava errado. Estes não devem ser ignorados e devem ser nomeados a fim de que o terapeuta possa levá-los em consideração" (T.A.). Parte da linguagem da unidade era "você tem que acreditar..." (T.A.). Isso significa acreditar na família e que "por detrás de tudo aquilo que (a família) já havia passado, ou seja, as situações estressantes, havia intenções positivas" (T.A.). Inclusa estava a crença em que "as pessoas não vão à terapia se não tiverem o desejo de mudar" (T.B.). Ouvir, levar a sério e acreditar nas pessoas foi considerado fundamental no processo de ajudar os clientes a formularem verbalmente suas vidas. É muito comum haver opiniões e sentimentos que ainda não foram traduzidos verbalmente. O terapeuta leva a sério tal ocorrência e acredita nos sinais e dicas pelas quais esse material "ainda não expresso" era manifestado e a família tinha a oportunidade de formular e explorar seu significado.

Flexibilidade foi definida da seguinte forma: "Desde o início, creio eu, estávamos bem preocupados em prestar atenção nos desejos da família e no significado da palavra 'flexibilidade'. Nos últimos anos começamos a falar em terapia sob medida" (T.B). Associada a isso estava a intenção central da Unidade "de não nos livrarmos do cliente, 
mas, ao contrário, como poderíamos planejar nosso tratamento a fim de que servisse às famílias" (T.A.). Portanto, a escolha do método e o contexto do trabalho terapêutico estavam sempre contingentes às preferências da família. Uma questão levantada era quanto ao local do tratamento. "Experimentaríamos algo diferente ou veríamos algo diverso em suas casas? Estou sempre curioso para saber o que pode emergir de lá. É nesse local que (a família) tenta as coisas e vê o que funciona" (T.C.). Assim, trabalhar fora da Unidade, no lar, na escola e em outros contextos foi importante para os terapeutas. A respeito do método de tratamento e da forma de se trabalhar, esses profissionais disseram: "escolhemos o que pensávamos, acreditávamos, esperávamos ou sentíamos a respeito da família, e... com o tempo começamos a utilizar métodos diferentes" (T.B.). Essa é a parte da "caixa grande de ferramentas", mas eles deixam claro que tal escolha de método sempre estava relacionada com as preferências e metas da família. Isso significava que o que o terapeuta via como a melhor forma de tratamento geralmente tinha que ser alterado, pois "o que vinha à tona nos fazia ver que (para aquela família) não seria possível seguir aquele caminho" (T.B.). Flexibilidade e tratamento sob medida significaram que estávamos dispostos a abrir mão ou adiar nossas próprias preferências terapêuticas para seguirmos a família; eram o sustentáculo do nosso trabalho naquela unidade.

A fonte do conceito de generosidade foi a estudante de terapia (T.D.). Ao descrever seus colegas de trabalho, declarou: "Eles mostram generosidade. Vejo como se relacionam com as famílias, sem julgamento, atentos e sempre pedindo um feedback". Apesar de generosidade ser uma palavra que seria muito difícil que esses terapeutas usas- sem para se descreverem, certamente concordariam que a generosidade é um valor importante a ser buscado. "Uma vez que temos uma superestrutura no conceito da própria teoria do cliente sobre mudança... necessitamos desenvolver e expandir nosso repertório continuamente" (T.A.). Uma forma de entender esta declaração sobre a relação com as famílias foi que esta comunicava generosidade com elas.

\section{A perspectiva da família}

Conversa, participação e relacionamento úteis foram os principais elementos na perspectiva da família. Conversação útil foi mais bem definida como fazer perguntas, dar tempo, proporcionar uma estrutura de trabalho, dar e receber feedback e reformulação. Participação útil foi caracterizada pelo uso do conhecimento profissional, ter muitas possibilidades e entendimento através da participação. Central para o relacionamento útil era ouvir, levar em conta e acreditar, ser flexível e a posição do terapeuta em lutar contra violação, disparidade e degradação.

Todas as famílias foram representadas com declarações e unidades de significado nas três categorias principais. Houve variação nas preferências e necessidades das várias famílias. A seguir usaremos as expressões: "todas as famílias" para nos referirmos às 10 famílias; "a maiorias das famílias" para indicar 8 ou 9 famílias e "algumas famílias" par nos referirmos a 6 ou 7 (Tabela 4).

A palavra "eficaz" faz parte do vocabulário dos terapeutas e dos pesquisadores, porém não foi usada por nenhuma das famílias entrevistadas. Nas entrevistas, "ajuda" era uma palavra recorrente, como em: "precisamos receber ajuda naquilo que estamos 
Tabela 4

\begin{tabular}{|c|c|c|}
\hline Conversação útil & Participação útil & Relacionamento útil \\
\hline $\begin{array}{c}\text { Fazer perguntas, dar } \\
\text { tempo, proporcionar } \\
\text { uma estrutura de } \\
\text { trabalho } \\
\text { (10 famílias) }\end{array}$ & $\begin{array}{c}\text { Usar o conhecimento } \\
\text { profissional } \\
\text { (10 famílias) }\end{array}$ & $\begin{array}{c}\text { Gerar colaboração } \\
(10 \text { famílias })\end{array}$ \\
\hline Dar e receber feedback & Ter muitas possibilidades & Dar de si \\
(8 famílias) & (10 famílias) & (6 famílias) \\
\hline Reformulação & $\begin{array}{c}\text { Entender através da } \\
\text { participação }\end{array}$ & $\begin{array}{c}\text { Lutar contra a } \\
\text { violação, disparidade e } \\
\text { degradação }\end{array}$ \\
(6 famílias) & (8 famílias) & famílias) \\
\hline
\end{tabular}

fazendo errado" (Família 10, a partir daqui F10, F1, F2, etc). Para o vocabulário das famílias, os ingredientes de uma terapia eficaz são aqueles que incluem a "ajuda" necessária.

No item "conversação útil", todas as famílias mencionaram especialmente a importância do terapeuta em fazer perguntas, dar tempo para reflexão e estruturar o trabalho. "N.N. fazia perguntas e cavava fundo ... a terapia foi muito profunda...” (F1). As famílias associaram profundidade com tempo para pensar, não ter que dar respostas rápidas, poder pensar e repensar suas respostas e não apressar as coisas. Um ponto importante: essas conversas levaram à estruturação do trabalho, não só sobre o que seria trabalhado, mas como isso seria feito. Palavras-chave e expressões que descrevem este item foram: direcionar, guiar, focar, sugerir e manter o plano.

Dar é receber feedback foi uma das atividades significativas apontadas pela maioria das famílias e, embora o feedback para os terapeutas seja considerado importante, a maior preocupação era receber o feedback do terapeuta: "Talvez o que eu mais tenha sentido falta tenha sido receber mais feedbacks; o que eu fiz estava certo? O que estou fazendo agora está correto ou posso fazê-lo de outro modo?" (F10). Alguns dos membros das famílias disseram que o terapeuta poderia tê-los informado melhor a respeito de aspectos negativos das interações familiares. Palavras-chave foram: estado, ser direto e específico. $\mathrm{O}$ foco de estar nos erros, mas de uma forma amigável e não humilhante.

Reformulação foi citada por algumas famílias. "Eles são bons em nos fazer reformular o que dizemos, repetidas vezes perguntavam: eu entendi o que disse corretamente? Ou o que você quer dizer com isso?" (F7). Palavras-chave foram: afirmação, prover diferentes ângulos de visão, criar distância, juntar as peças do quebra-cabeça. Reformulação conduz a mudanças de perspectiva e também de significado...: "quando me sentia um fracasso em algo, eles enxergavam a situação por um outro ângulo... mais positivo.. quando você recebe constantemente esse tipo de apoio, sente o desejo de fazer melhor" (F2).

"A participação útil" foi baseada no conselho das famílias, que era o de que o terapeuta deveria participar 
ativamente no trabalho e proporcionar outras oportunidades além de falar e conversar. Foi muito importante ser capaz "...de nos expressarmos... fazendo coisas...” (F1). As famílias convidaram os terapeutas a usarem o conhecimento profissional para realizar atividades como brincadeiras, jogos, competições, trabalhos com arte, teatro de marionetes, dramatização, caminhadas e gravação de vídeos. Adultos e crianças consideraram necessário fazer algo mais do que falar. Tal atitude comprometeu mais profundamente todos os envolvidos no trabalho e aumentou as possibilidades de trabalharem com o 'aqui e agora', por exemplo, "...cuidar das coisas assim que elas aparecem" (F3) e resolver os problemas imediatamente.

Conhecimento profissional auxiliou tanto os terapeutas como as famílias a verem a situação familiar de fora e deu aos terapeutas a posição de autoridade profissional. As famílias viram esta autoridade como necessária em todos os aspectos da vida familiar; externamente, ao obter os recursos necessários das agências sociais, especialmente em situações de conflito entre a família e o 'sistema'. Aqui o terapeuta representa a família: "o relatório profissional... foi a carta do coringa... com a qual nós podíamos ganhar o jogo" (F3). Internamente, essa autoridade fornecia à família informações e transparência com respeito às intenções, perspectivas e pensamentos do terapeuta. Ao mesmo tempo, houve relatórios nos quais mais informações poderiam ter sido dadas. "No começo, não recebemos tantas informações. Como o dia e o trabalho seriam organizados poderiam ter sido passados para nós" (F3).

Ter muitas possibilidades foi muito importante para todas as famílias, o que incluía: onde, quando, por quanto tempo, como e com quem trabalhar.
Esta unidade da família teve a oportunidade de ultrapassar os contextos e períodos tradicionais de tratamento, uma característica muito valorizada por todas as famílias. Hospedar-se na unidade foi "...uma lufada de ar fresco" (F5). As famílias enfatizaram a oportunidade de participação da larga rede de profissionais e da família estendida. Envolver os parentes foi “...saudável na maioria dos casos, porque a parentela ficou comovida (com o problema) $e$, também, porque constituíam uma parte significativa da vida das crianças" (F9). A organização do trabalho terapêutico incluiu a divisão da família em subgrupos, o que permitiu que os pais trabalhassem separadamente e, ao mesmo tempo, soubessem que seus filhos também estavam sendo cuidados. O contexto mais importante fora da família era a escola. Estabelecer um relacionamento de confiança e colaboração foi um dos objetivos essenciais de todas as famílias.

Entender por meio da participação era altamente estimado pela maioria das famílias. A participação em situações similares a aquelas da família era geralmente a de fracasso, tanto para os usuários dos serviços quanto para os terapeutas. A palavra-chave era compartilhar experiências. "Você não precisa se afogar para ser um salva-vidas, mas precisa, pelo menos, ter uma ideia" (F5). Participação não significa ter passado exatamente pela mesma experiência, mas se colocar no lugar da família. Os pacientes percebiam o 'entender por meio da participação' do terapeuta imediatamente; por atitudes não verbais eles compreendiam que sua experiência ressoava no terapeuta: "Eu só precisava olhar para ele (o terapeuta), (eu sabia) que ele simplesmente sabia" (T6).

"O Relacionamento útil" implica ser ouvido, escutado, ser levado a sé- 
rio, que acreditem em você e poder seguir os objetivos e métodos que preferir. O terapeuta que demonstra isso é considerado uma pessoa confiável: "É frustrante não se sentir confiável... Acho que isso é da mais alta importância" (F6). Ao seguir os desejos, perspectivas e preferências da família, o terapeuta reafirma essas experiências. Quando isso não acontece é importante que o terapeuta assuma o erro. Por exemplo, quando o terapeuta diz que a mãe "...não deveria excluir a possibilidade de ele estar errado" (F6), tal atitude dissolve a tensão e se torna um passo na direção correta de um relacionamento de trabalho útil.

A conduta pessoal do terapeuta era vital na criação de um relacionamento colaborativo. Ser calmo, paciente, amigável, fácil de se lidar, sem julgamentos, humano e, acima de tudo, ter senso de humor fazia dos terapeutas "pessoas fáceis de se trabalharem" ...(F4). Não ter preconceitos e ser sincero eram fundamentais. O preconceito foi associado a "ser o sabichão" e olhar de cima para baixo para a família". (Os terapeutas) "pediam desculpas... e nos ouviam. Achei muito bom eles admitirem que estavam errados... porque... geralmente temos a sensação... que as autoridades não cometem erros. Eles desceram ao nosso nivel..." (F10).

Para algumas famílias, dar de si mesmo era considerado importante. Isso tinha a ver com o terapeuta contar algo de si mesmo e usar histórias de sua própria vida. "O que permitiu que nos comunicássemos foi o fato de ele se referir à sua própria família e ter usado muitos exemplos dele mesmo, de sua esposa, filhos ..." (F5). Isto foi sentido como sendo um fator que fortaleceu o elo entre a família e o terapeuta, o que resultou em maior colaboração entre ambos.
Algumas famílias relataram experiências marcantes de quebra de confiança, disparidade e diminuição em seus contatos com escolas, serviços de cuidado à criança e saúde mental. Ser ignorado, visto de uma forma negativa e uma atmosfera de desdém caracterizavam tais experiências. " $O$ doutor me dava a impressão de que eu era histérica e nervosa, quem precisava de tratamento era eu..." (F8). Esses elementos foram prejudiciais a posteriores contatos ou trabalhos terapêuticos. Eles se tornaram em si mesmos patogênicos. As famílias apontaram que, para estabelecer um relacionamento útil, os terapeutas devem ter uma posição claramente contrária a essas práticas; eles devem lutar contra elas e devem se assegurar de que a credibilidade da família seja restabelecida, principalmente daqueles que sofreram tal abuso.

\section{DISCUSSÃO}

Observar as perspectivas tanto dos terapeutas quanto das famílias é um exemplo de "dupla descrição" (Bateson, 1980). Dupla descrição refere-se ao enriquecimento de um fenômeno ao se permitir que os aspectos de dualidade se complementem de forma mútua. Tais descrições são conectadas por suas similaridades e enriquecidas por suas diferenças. Entre as similaridades, três conceitos podem ser extraídos de ambas as descrições. Estes são: conversação, participação e relacionamento, os quais coincidem com os ingredientes úteis de uma terapia salientados pelas famílias. Da descrição dos terapeutas temos: "sentir na pele" sob o conceito de participação e "estar onde as pessoas estão" sob relacionamentos. A metáfora dupla de "uma conversa sem pressa e um caixa grande 
de ferramentas" pode ser dividida em conversação e participação. Abaixo os conceitos de conversação, participação e relacionamento são desenvolvidos, prestando atenção a suas similaridades e diferenças.

\section{Similaridades de Perspectivas}

O conceito de conversação é ressaltado em ambas as perspectivas, em especial, pela importância das perguntas e do tempo para a resposta. O conceito de participação abarca a capacidade do terapeuta de influenciar o problema e a situação familiar através do conhecimento específico que possuem (Famílias) e ter uma caixa grande de ferramentas (Terapeutas). Há um consenso de que os terapeutas devem disponibilizar às famílias seus conhecimentos, devem ser transparentes sobre o que pensam e a ação a ser tomada, o que seus conhecimentos lhes sugerem e, ainda, não devem desqualificar as perspectivas das famílias, pois saber mais não significa necessariamente saber melhor. Ademais, o conceito de participação aponta para ter muitas possibilidades (família), ser flexível (terapeutas) e compartilhar experiências (Famílias/terapeutas), principalmente por parte do terapeuta.

$\mathrm{O}$ conceito de relacionamento recebeu um forte apoio em ambas as perspectivas. "Estar onde as pessoas estão" (terapeutas) e criar colaboração (famílias) enfatizam: ouvir, levar a sério, acreditar, estabelecer/seguir os objetivos e métodos das famílias e usar o conhecimento do terapeuta em uma sociedade colaborativa. $\mathrm{O}$ valor depositado na generosidade (terapeutas), dar de si (famílias) e o desejo de diminuir as diferenças entre terapeutas e famílias (terapeutas) fortalecem o compromisso de tal relacionamento.
Diferenças entre perspectivas

As diferenças entre as perspectivas enriquecem os três conceitos. A conversação é enriquecida pela diferença de foco em relação ao uso do feedback. Os terapeutas estavam comprometidos com o monitoramento do trabalho deles e a ajustá-lo de acordo com o feedback sobre processos e resultados. As famílias reconheceram esse fato, mas deram uma mensagem clara que o que elas precisavam era de um feedback dos terapeutas sobre os aspectos negativos de suas interações familiares. O terapeuta era visto como uma pessoa que os apoiava, então o foco deles nos aspectos negativos seria seguro. $\mathrm{O}$ treinamento em terapias voltadas para a linguagem (Flaskas, 2002) enfatiza a desconfiança de se rotular uma família como "problemática" e a promoção de uma visão mais positiva (Palazzoli, 1978). A mensagem das famílias foi a de que os terapeutas não deveriam temer focalizar os pontos negativos, desde que isso fosse feito dentro de contexto de "um relacionamento útil", como descrito acima. O que sugere que o contato anterior com os serviços sociais não foi considerado como sendo um "relacionamento útil".

O conceito de conversação foi enriquecido posteriormente com a inclusão da importância de se ter um trabalho estruturado. Embora novas ideias e formas de trabalhar durante o curso da terapia fossem apreciadas, eles claramente queriam um plano de tratamento com objetivos, métodos e a participação ativa do terapeuta que guiaria, incentivaria e influenciaria o trabalho terapêutico de acordo com o planejado. Fazer perguntas, dar tempo para as respostas e estruturação do trabalho exemplificam isso. Fazer perguntas era um processo vagaroso no qual cada resposta era governada 
pela anterior. Era um processo exploratório com um fim em aberto. Entretanto, após um tempo, um foco devia ser estabelecido. Focalizar em um aspecto particular faz com que perguntas quanto a ações concretas comecem a surgir, assim como a necessidade de uma estrutura para o tratamento. Nessa fase, o uso do flip chart foi muito apreciado. Apesar de a estrutura poder ser considerada como parte da perspectiva do terapeuta, ela se tornou muito mais clara na perspectiva das famílias. Por último, algumas famílias apontaram para a importância da reformulação dos eventos e comportamentos familiares por parte dos terapeutas. As reformulações foram sentidas como oportunidades para novas experiências e pontos de vista. A importância da reformulação confirma o foco das terapias focadas na linguagem, construção de significado e a criação de significados novos e alternativos (Anderson \& Gehard, 2007).

O conceito de participação foi expandido por uma diferença em relação à falta de informações, especialmente no início do tratamento. Por exemplo, uma família recomendou a produção de uma brochura explicando a prática da Unidade. Como os terapeutas foram treinados para assumirem uma posição de "não saber" (Anderson \& Gehard, 2007), foi importante que reconhecessem cada família como um grupo único, sem lhes impor seus próprios entendimentos. Mesmo não negando seu conhecimento profissional, os terapeutas podem não o ter comunicado apropriadamente aos pacientes. As famílias deixaram claro que eles não precisavam ter medo de perder de vista o caráter único das mesmas ao apresentarem um conhecimento generalizado. Novamente, "o relacionamento útil" assegurava às famílias essa sensação de singularidade. Assim, a conclusão é que os terapeutas devem ser tão transparentes quanto possível a respeito de seus conhecimentos e experiências.

O conceito de relacionamento foi enriquecido pelo fato de algumas famílias terem relatado experiências traumáticas de violação, disparidade e diminuição que sofreram nos serviços de educação, de saúde e sociais. Isso é um lembrete de que terapia e cuidados médicos podem se tornar danosos. Quando o relacionamento entre profissionais e famílias se torna o oposto de "relacionamento útil", medidas adequadas de solução de problemas e novos tratamentos ficam comprometidos. Ademais, a própria experiência torna-se patogênica. Os pacientes confirmaram elementos terapêuticos como "estar onde as pessoas estão" e "sentir na pele", ressaltando a importância de tais processos. A mensagem aos terapeutas foi clara: participar a favor das famílias e ser seus agentes diante do sistema. Isso apoia as conclusões de Gehard e Lucas (2007) sobre a defesa do paciente.

Neste estudo, os diferentes aspectos de conversação, participação e relacionamento têm sido entremeados e entrelaçados em diversas constelações úteis - de acordo com as preferências e perspectivas da família. Ademais, o uso do conhecimento profissional, a criação de estrutura e o fornecimento de feedbacks sobre os aspectos problemáticos das interações familiares estão embutidos e delimitados em relacionamentos úteis. Esses conceitos identificam as áreas principais em relação à prática, pesquisa e treinamento clínicos, os quais serão tratados a seguir.

O conceito de relacionamento neste estudo é paralelo às conclusões de Nortcross (2000), mas também sugere que deveria ser dada atenção a algu- 
mas ampliações no trabalho, treinamento e pesquisa clínicos. Isso reflete a importância da aliança terapêutica (Horwath \& Bedi, 2002), autorrevelação (Hill \& Knox, 2002) e ressalta a importância de se privilegiar a perspectiva do paciente. Uma expansão do conceito de relacionamento é a do papel do terapeuta em tomar uma parte ativa na resolução de conflitos entre a família e outras partes do sistema de saúde, assistência social e escolas, a fim de restabelecer a honra e a colaboração da família com os mesmos. Isso implica a expansão do treinamento do terapeuta, incluindo gerenciamento de conflito e desenvolvimento de habilidades como agente apoiador da família. Portanto, pesquisas sobre quais habilidades seriam necessárias em tais situações são altamente recomendáveis. Essa questão também convida a mais pesquisas quanto aos resultados prejudiciais das atividades terapêuticas, assim como dos comportamentos positivos dos sistemas de assistência.

Dentro do relacionamento útil, atividades terapêuticas mais especificamente orientadas podem e devem ser implementadas. O conceito de conversação dirige a atenção para todo processo verbal no relacionamento, mas aponta para duas possibilidades opostas: (a) um processo aberto, composto por perguntas e tempo de reflexão das respostas, e (b) um processo estruturado ou baseado em algum tipo de estrutura. Isso indica a necessidade de treinamento envolvendo o gerenciamento de tais processos potencialmente conflitantes. Rever a pesquisa já realizada (Lambert \& Ogles, 2004) dá ao terapeuta muitas informações quanto ao uso de processos terapêuticos específicos, mas parece haver uma lacuna na pesquisa quanto aos efeitos de um processo mais aberto e sua implementação com um trabalho estru- turado. Portanto, pesquisas adicionais são necessárias.

Pesquisa a respeito do feedback de pacientes (Claiborne, Goodyear, \& Horner, 20002) e de terapeutas (Lambert \& Ogles, 2004) é enfatizada na pesquisa psicoterapêutica, porém parece haver uma falta de estudos relatando as experiências de fornecedores e recebedores do feedback. Mais conhecimento poderia nos guiar em como treinar os terapeutas no uso de feedback, em especial aqueles que estão constantemente monitorando terapias.

Reformulação é provavelmente parte de todos os trabalhos terapêuticos, embora apresentada em conceitos diferentes: redefinição, dar sentido, interpretação e entendimento. Neste estudo, a importância da reformulação deve ser entendida dentro do campo do relacionamento útil. A reformulação deve ser adaptada ao paciente, a fim de que suas perspectivas sejam privilegiadas e enaltecidas. Isso é mais fácil dizer do que fazer, o que indica que uma das tarefas centrais do treinamento de terapeutas é a criação de habilidades que permitam aos mesmos apresentarem algo novo e, ao mesmo tempo, apoiar a posição e as perspectivas da família.

Como foi dito acima, existe a possibilidade de termos de lidar com aspectos que podem ser considerados conflitantes pelos terapeutas. Tais processos foram incluídos no conceito de participação. As terapias orientadas linguisticamente e as colaborativas, (Andersen, 1991; Anderson \& Gehart, 2007; White, 2007) orientadoras desta Unidade, têm um relacionamento complexo com os aspectos técnicos da terapia. Diz Andersen: "A terapia não é uma técnica. É uma forma de o terapeuta engajar-se nos relacionamentos do paciente" (1993, p. 305). O temor é que o uso de ferramentas e técnicas 
transforme a relação terapêutica em um relacionamento meramente instrumental, no qual os integrantes da família se tornem objetos de escrutínio, resultando na "objetificação" das pessoas e dos relacionamentos. Nesse estudo, as famílias esperavam que os terapeutas fossem competentes, tivessem conhecimento e soubessem usá-lo. Ainda nesse estudo, o que os terapeutas pudessem temer como prejudicial a um relacionamento útil era tomado como certo pelas famílias. Para elas, era natural que os terapeutas usassem e compartilhassem o que sabiam. Ser capaz de realizá-lo seria um dos objetivos do treinamento e também um convite para mais pesquisas no uso de conhecimento especializado dentro de um relacionamento colaborativo de terapia.

O conceito de participação também apontou para a necessidade de estarem juntos nas situações e experimentar algumas das mesmas coisas. Ser pessoal e ter a permissão de envolver-se são habilidades básicas e os terapeutas deveriam ter situações de treino para desenvolver tal capacidade de envolvimento pessoal. O conceito de sintonia efetiva (Stern, 1985) da psicologia do desenvolvimento enfatiza as habilidades humanas desenvolvidas muito tempo antes do início do treinamento como terapeuta. Portanto, o treinamento deveria focar em como transformar essas qualidades inatas ou aprendidas previamente em competências terapêuticas e pesquisas nesse campo deveriam ser consideradas uma meta importante dentro do campo psicoterapia.

\section{Contexto para mudanças}

As mudanças que as ideias tiradas de modelos haviam passado eram contingentes ao contexto da Unidade da Família. Particularmente importante foram os problemas enfrentados pelas famílias e terapeutas: Transtorno de Déficit de Atenção com Hiperatividade (TDAH), Transtorno Obsessivo-Compulsivo (TOC), além de problemas de conduta e de desenvolvimento que levantam desafios específicos e são caracterizados por relacionamentos interpessoais deficientes. O que é evocado no terapeuta por esses tipos de interações aumenta sua conscientização do impacto do problema e a identificação daquilo que é prejudicial na forma de se trabalhar com as famílias. Ampliar a perspectiva conversacional das fontes úteis para a prática terapêutica, a fim de incluir práticas orientadas para a ação e a participação real do terapeuta, pode se vista como uma resposta a tais experiências problemáticas. Ao se trabalhar com problemas comportamentais, o terapeuta precisa de outras ferramentas além da fala; a escolha de incluir uma dramatização pode ser vista como uma consequência de se trabalhar com problemas de comportamento. Muitas das famílias assistidas pela Unidade tinham também tentado programas terapêuticos em outras instituições - sem resultado. Portanto, a necessidade de formas alternativas de prática foi fortalecida. Guiados pelas preferências e ideias das famílias, alteração e expansão das ideias e práticas orientadoras iniciais podem, portanto, ser esperadas.

\section{CONCLUSÃO}

Conversação, participação e relacionamento são apresentados neste estudo como três conceitos amplos, cujas especificações dão a definição de terapia útil. A importância da natureza co- 
laborativa dos modelos que têm guiado esta Unidade é confirmada, mas, ao mesmo tempo, há a necessidade de expansão dos mesmos em duas direções importantes. Primeira, a orientação linguística dos modelos norteadores deve ser expandida para incluir práticas terapêuticas orientadas para a ação. Segunda, o conhecimento profissional e as habilidades do terapeuta não estão em oposição à posição de não especialista e não saber desses modelos. Ao contrário, quando embutidos em um relacionamento útil, as habilidades e conhecimento do terapeuta se tornam ferramentas essenciais para as famílias usarem através da transparência e participação do terapeuta. Há um claro imperativo aos terapeutas com respeito à pesquisa e treinamento: criar e acessar tantas habilidades quanto possível e fazê-lo nas áreas destacadas pelos conceitos de conversação, participação e relacionamento.

\section{REFERÊNCIAS}

Andersen, T. (1991). The reflecting team: Dialogues and dialogues about the dialogues. New York: Norton Press.

Andersen, T. (1993). See and hear, and be seen and heard. In S. Friedman (Ed.), The New Language of Change. Constructive Collaboration in Psychotherapy (pp. 303-322 ). New York: The Guilford Press.

Anderson, H. (1996). A reflection on client-professional collaboration. Families, Systems \& Health, 14, 193-206.

Anderson, H. \& Goolishian, H. A. (1988). Human systems as linguistic systems: Preliminary and evolving ideas about the implications for clinical theory. Family Process, 27, 371-393.
Anderson, H. \& Gehart, D. (Eds.). (2007). Collaborative Therapy: Relationships and conversations that make a difference. New York: Routledge.

Balmbra, S. (2006). User Guidelines for Family Dialogue Set. Recuperado de http://www.balmbra.no/Family\%20 Dialogue\%20Set/eng/ fds\%20eng. htm

Barkley, R. A. (1997). Defiant Children: A Clinician's manual for assessment and parent training. New York: Guilford Press.

Bateson, G. (1980). Mind and nature: A necessary unity. Toronto: Paladin.

Bennett, L. (2008). Narrative methods and children: Theoretical explanations and practice issues. Journal of Child and Adolescent Psychiatric Nursing, 21(1), 13-23.

Claiborne, C. D., Goodyear, R. Kr, \& Horner, P. A. (2002). Feedback. In J. C. Norcross (Ed.), Psychotherapy relationships that work. Therapist contributions and responsiveness to patients. (pp. 217-233). New York: Oxford University Press.

Elliott, R., Fischer, C. T., \& Rennie, D. L. (1999). Evolving guidelines for publication of qualitative research studies in psychology and related fields. British Journal of Clinical Psychology, 38, 215-229.

Flaskas, C. (2002). Family therapy beyond postmodernism: Practice challenges theory. New York: Brunner-Routledge.

Gehart-Brooks, D. R. \& Lyle, R. R. (1999). Client and therapist perspectives of change in collaborative language systems: An interpretative ethnography. Journal of Systemic Therapies, 18(4), 58-77.

Gehart-Brooks, D. R., Ratliff, D. A., \& Lyle, R. R. (2001). Qualitative research in family therapy: A substantive and methodological re- 
view. Journal of Marital and Family Therapy, 27(2), 261-274.

Gehart, D. R. \& Lucas, B. M. (2007). Client advocacy in marriage and family therapy: A qualitative case study. Journal of Family Psychology, 18(1), 39-56.

Glaser, B. G. \& Strauss, A. L. (1968). The discovery of grounded theory: Strategies for qualitative research. London: Weidenfeld and Nicholson.

Hill, C. E., Thompson, B. J., \& Williams, E. N. (1997). A guide to conducting consensual qualitative research. The Counseling Psychologist, 25, 517-572.

Hill, C. E. \& Knox, S. (2002). Self-disclosure. In J. C. Norcross (Ed.), Psychotherapy relationships that work: Therapist contributions and responsiveness to patients (pp. 255265). New York: Oxford University Press.

Horvath A. 0. \& Bedi, R. P. (2002). The Alliance. In J. C. Norcross (Ed.), Psychotherapy relationships that work: Therapist contributions and responsiveness to patients (pp. 3769). New York: Oxford University Press.

Kvale, S. (1996). Interviews: An introduction to qualitative research interviewing. Thousand Oaks, CA: Sage Publications.

Lambert, M. J., Bergin, A. E., \& Garfield, S. L. (2004). Introduction and historical overview. In M. J. Lambert (Ed.), Bergin and Garfield's handbook of psychotherapy and behavior Change ( $5^{\text {th }}$ ed, pp. 3-15). New York: John Wiley and Sons, Inc.

Lambert, M. J. \& Ogles, B. M. (2004). The efficacy and effectiveness of psychotherapy. In M. J. Lambert (Ed.), Bergin and Garfield's handbook of psychotherapy and behavior Change (5 $5^{\text {th }}$ ed., pp. 139-193). New York: John Wiley and Sons, Inc.
London, S., Ruiz, G., \& Gargollo, M. (1998). Clients' voices: A collection of clients' accounts. Journal of Systemic Therapies, 17(4), 61-71.

McGoldrick, M., Gerson, R., \& Shellenberger, S. (1999). Genograms: Assessment and intervention. New York: Norton Press.

McNamee, S. (2004). Promiscuity in the practice of family therapy. Journal of Family Therapy, 26(3), 224-244.

Miller, S. D. \& Duncan, B. L. (2004). The outcome and session rating scales: Administration and scoring manual. Chicago: Institute for the Study of Therapeutic Change.

Nerdrum, P. \& Rønnestad, M. H. (2002). The trainees' perspective: A qualitative study of learning empathic communication in Norway. The Counseling Psychologist, 30, 609-629.

Norcross, J. C. (Ed.). (2002). Psychotherapy relationships that work. Therapist contributions and responsiveness to patients. New York: Oxford University Press.

0'Connor, T. S., Meakes, Ex, Pickering, M. R., \& Schuman, M. (1997). On the right track: Client experience of narrative therapy. Contemporary Family Therapy, 19(4), 479-495.

0'Connor, T. S., Davis, A.s Meakes, Ery Pickering, M. R., \& Schuman, M. (2004). Narrative therapy using a reflecting team: An ethnographic study of therapists' experiences. Contemporary Family Therapy, 26(1), 23-39.

Palazzoli, M. S. (1978). Paradox and counter paradox. New York: Jason Aronson.

Pinsof, W. M. \& Wynne, L. C. (2000). Toward progress research: Closing the gap between family therapy practice and research. Journal of Marital and Family Therapy, 26(1), 1-8.

Rennie, D. L.s Phillips, J. R.s \& Quartaro, G. K. (1988). Grounded theory: 
A promising approach to conceptualization in psychology. Canadian Psychology/Psychologie Canadienne, 29(2), 139-150.

Rennie, D. L. (1992). Qualitative analysis of the client's experience of psychotherapy: The unfolding of reflexivity. In S. G. Toukmanian \& D. L. Rennie (Eds.), Psychotherapy Process research: Paradigmatic and narrative approaches (pp. 211233). Newbury Park, CA: Sage Publications.

Rennie, D. L. (2000). Grounded theory methodology as methodical hermeneutics. Theory \& Psychology, 10, 481-502.

Schutz, A. (1967). The phenomenology of the social world. Evanston, IL: Northwestern University Press.

Sells, S. Pr, Smith, T. E., Coe, M. J., Yoshioka, M., \& Robbins, J. (1994). An ethnography of couple and therapist experiences in reflecting team practice. Journal of Marital and Family Therapy, 20(3), 247-266.

Smith, T. E., Sells, S. Pr, \& Clevenger, T. (1994). Ethnographic content analysis of couple and therapist perceptions in a reflecting team setting. Journal of Marital and Family Therapy, 20(3), 267-286.

Seikkula. J. \& Arnkil, T.E. (2006). Dialogical Meetings in Social Networks. London:

\section{Karnac.}

Smith, T. E., Winton, M., \& Yoshioka, M. (1992). A qualitative understanding of reflecting teams II: Therapists' perspectives. Contemporary Family Therapy, 14(5), 419-432.

Smith, T. E., Yoshioka, M., \& Winton, M. (1993). A qualitative understanding of reflecting teams I: Client perspectives. Journal of Systemic Therapies, 12(3), 28-43.

Stern, D. N. (1985). The Interpersonal World of the Infant: A View from
Psychoanalysis and Developmental Psychology. New York: Basic Books. White, M. (2007). Maps of narrative practice. New York: W.W. Norton \& Company.

\section{ROLF SUNDET}

Psicólogo clínico. Atua na Unidade da Família - Departamento de Psiquiatria da Criança e do Adolescente, Hospital de Buskerud, Drammen; Pesquisador do Departamento de Saúde, Universidade de Buskerud, Drammem, Noruega.

$\mathrm{O}$ autor gostaria de agradecer à professora Sissel Reichelt por sua valorosa contribuição e apoio.

Endereço para correspondência: Department of Health, University College of Buskerud, Gronnland 58, 3045, Drammem, Norway. 